\title{
Further evidence for priming in perceptual matching: Temporal, not spatial, separation enhances the fast-same effect
}

\author{
MARK H. CHIGNELL and LESTER E. KRUEGER \\ Ohio State University, Columbus, Ohio
}

\begin{abstract}
Sequential (vs. simultaneous) presentation of two letters in a physical-identity matching task enhanced the fast-same effect, but did not reduce the preponderance of false "different" errors or the effect of visual similarity. Thus, the sequential enhancement of the fast-same effect involves an increased efficiency in encoding $\left(d^{\prime}\right)$ owing to letter repetition, as Proctor claimed, rather than a criterion shift $(\beta)$, and it involves the visual code rather than the name code. The increased efficiency in detecting sameness with sequential presentation might result from spatial separation (e.g., reduced lateral interference and self-termination), though, rather than temporal separation (e.g., priming). However, such spatial factors as letter size and interletter spacing had no consistent effect on the speed advantage for same pairs, and it was concluded that temporal, not spatial, separation enhances the fast-same effect on sequential trials. Consistent with the response-competition model (Eriksen, O'Hara, \& Eriksen), responses were slower and more errorful to similar than to dissimilar different pairs, and were equally fast to dissimilar and same pairs on simultaneous trials.
\end{abstract}

In a physical-identity matching task, two letters are judged "same" if identical and "different" if not. Same judgments typically are faster than different judgments, especially if the two letters are presented sequentially, that is, one after the other, rather than simultaneously (Proctor, 1981). Understanding why sequential presentation enhances the fast-same effect may provide important insight into the matching process. The primary objective of the present study was to determine whether and why sequential enhancement occurs. Three successive questions are addressed: (1) Does sequential enhancement of the fastsame effect occur? (2) Does it involve an increased efficiency in encoding $\left(d^{\prime}\right)$ due to letter repetition or a criterion shift $(\beta)$ ? (3) If it involves increased efficiency, does it depend on temporal separation (e.g., priming) or spatial separation (e.g., reduced lateral interference and self-termination)? When two letters are shown sequentially, not only is temporal contiguity lost, but so also is spatial contiguity; to unconfound matters, the spatial factor was tested separately.

This study was supported by a postdoctoral fellowship to Mark H. Chignell from the Graduate School, Ohio State University. The authors are grateful to Mary Pejeau for assistance in collecting the data, and to Robert W. Proctor for helpful comments on an earlier version of this report. Mark $\mathrm{H}$. Chignell is now at the Department of Industrial and Systems Engineering, University of Southern California, Los Angeles, CA 90089. Requests for reprints should be sent to Lester E. Krueger, Human Performance Center, Ohio State University, 404-B West 17th Avenue, Columbus, $\mathrm{OH} 43210$.

\section{Question 1}

Does sequential enhancement occur? Krueger (1983) found sequential enhancement only when intertrial letter repetition was minimized, which led him to doubt its existence. The present study provided a further opportunity to test for sequential enhancement when intertrial letter repetition was infrequent.

\section{Question 2}

Does sequential enhancement involve a sensitivity shift (d') or a criterion shift $(\beta)$ ? Proctor (1981; Proctor \& Rao, 1983c) proposed that letter repetition speeds encoding by increasing the rate at which information is built up, whereas Krueger and Shapiro (1981) proposed that the encoding of the first member of a pair biases the subject toward naming the second letter the same as the first. Such a criterion shift ought to produce more false-"same" responses (i.e., errors on different pairs), whereas a sensitivity shift ought not to alter the error disparity, assuming that errors arise primarily at the comparison stage, rather than at the encoding stage (which priming facilitates).

As evidence for a criterion shift, Krueger and Shapiro tallied previous studies and found a decided tendency for false-"different" errors to exceed false"same" errors with simultaneous presentation but not with sequential presentation. More recently, however, Krueger (1983) and Proctor and Rao (1983a) found no such change in the error tendency with sequential vs. simultaneous presentation, and both studies concluded that sequential enhancement in- 
volved a shift in encoding efficiency rather than in the criterion. The present study tests the robustness of this finding using a variety of display conditions.

\section{Question 3}

If a sensitivity shift occurs, does it depend on temporal separation or spatial separation? On sequential trials, not only is temporal contiguity lost, but so is spatial contiguity. A criterion shift seemingly would require time to occur, but a sensitivity shift, if found, might depend on spatial rather than temporal separation. In this study, we examined two spatial factors that might diminish the relative efficiency of detecting sameness (vs. difference) when the letters in a stimulus pair are spatially contiguous. First, lateral interference might be greater with closely spaced identical letters than with different letters, due to feature-specific lateral inhibition (Bjork \& Murray, 1977) or other factors (Estes, 1982). If so, then the fast-same effect should be diminished or reversed with close spacings. Second, spatial proximity may benefit the "different" response more directly by encouraging analytical, self-terminating comparison. That is, differences between letters lying next to each other might stand out, leading to an immediate "different" response as soon as a mismatching feature was detected, whereas a "same" response would be based, as usual, on an exhaustive comparison. If so, different trials would have an advantage at close spacings, thus diminishing or reversing the fast-same effect in that case.

Another indication of self-termination is provided by the effect of letter pair size. Our smallest and most closely spaced letter pairs fit within the irreducible minimum extent of 1 deg to which attention seemingly may be narrowed or focused (Eriksen \& Hoffman, 1973). Thus, the comparison likely was holistic rather than analytical on simultaneous as well as sequential trials (Krueger, 1983). If so, then, the fast-same effect should be diminished or reversed on simultaneous trials, due to self-termination, only with larger letter pairs. Previous work in which display size was varied indicates that the self-termination that occurs on simultaneous trials is greater than that which occurs on sequential trials with multiletter strings (Krueger, 1984), but not with single-letter strings (Krueger, 1983). This study provides a further test of the latter finding.

\section{Other Factors}

A secondary objective was to obtain data relevant to other models of the fast-same effect (Eriksen, O'Hara, \& Eriksen, 1982; Krueger, 1978). Similarity on different trials was varied. If the presence of matching features makes "different" judgments slower than "same" judgments, as proposed by Eriksen et al., then dissimilar different pairs, which contain few matching features, ought to be as fast as same pairs.
Similarity and letter size also were varied in order to test whether the same visual code is used on sequential and simultaneous trials (see Boles \& Eveland, 1983; Crist, 1981). If sequential comparisons are performed on name codes, as Proctor (1981) concluded, then visual similarity ought not to affect sequential trials.

Errors will be scrutinized carefully with respect not only to priming, but also to other explanations of the fast-same effect. A preponderance of false-"same" (vs. false-"different") errors would support Eriksen et al.'s response-competition model, since different pairs containing matching features would tend to activate the "same" response. However, Krueger (1983) and Proctor and Rao (1983a) found a preponderance of false-"different" errors, as would be expected if internal noise more often turned a physical match into a perceived mismatch than vice versa (Krueger, 1978).

A backward mask was used on some trials in Experiment 1 in order to increase the noise level and to limit the duration of rechecking of perceived differences. Insofar as rechecking is disabled, then, according to the noisy-operator theory (Krueger, 1978), the response-time (RT) disparity between same and different pairs ought to decrease, whereas the error disparity (i.e., preponderance of false-"different" responses) ought to increase, as Krueger and Shapiro (1982) found.

\section{EXPERIMENT 1}

\section{Method}

Subjects. Twenty Ohio State University undergraduates participated in order to receive credit in an introductory psychology course. Data from three additional subjects were discarded, two because of equipment failure and one for exceeding an $8 \%$ error criterion. All subjects had at least $20 / 30$ vision (corrected), as tested with a Snellen chart.

Apparatus. Uppercase letters were presented at a $60-\mathrm{Hz}$ refresh rate and at $32-c d / \mathrm{m}^{2}$ intensity on a greenish-tint, fast-decay P31 phosphor (decay to $1 \%$ intensity at $.25 \mathrm{msec}$ after display offset) by an Imlac PDS-4 graphics computer, which measured RT to an accuracy of $1 \mathrm{msec}$. The letters, presented as thin, illuminated lines on a dark screen, were software generated, using short line vectors, so as to resemble normal English uppercase letters. Each subject sat alone in a dark room, with the head held fast in a chinrest located $70 \mathrm{~cm}$ from the display screen.

Stimulus materials. Each letter was $.29 \mathrm{~cm}(.24 \mathrm{deg})$ wide and $.43 \mathrm{~cm}(.36 \mathrm{deg})$ high in the small-size condition and $.87 \mathrm{~cm}$ (.72 deg) wide and $1.29 \mathrm{~cm}(1.08 \mathrm{deg})$ high in the large-size condition. The spatial separation between letters in a pair was .1, .2, or $.5 \mathrm{deg}$. Beyond a separation of $.5 \mathrm{deg}$, little lateral interference would be expected to occur (Eriksen \& Rohrbaugh, 1970). The horizontal extent of the pairs varied between $.58 \mathrm{deg}$ (small size, .1-deg spacing) and $1.94 \mathrm{deg}$ (large size, .5-deg spacing). The stimulus-onset asynchrony (SOA) between letters in a pair was $0 \mathrm{msec}$ (simultaneous presentation) or $500 \mathrm{msec}$ (sequential presentation). The two letters were centered $0.3 \mathrm{~mm}$ above a small $(1.6 \times 1.6 \mathrm{~mm})$ plus sign, which was the fixation mark at the center of the screen.

The six letters used represented three similarity subsets: $\mathbf{H , M}$; O,D; L,T (cf. Estes, 1982). Each letter was chosen so as to be 
similar to the other member of its subset, but not to letters in the other two subsets, on the basis of previously published norms of letter similarity (Gilmore, Hersh, Caramazza, \& Griffin, 1979; Podgorny \& Garner, 1979; Shepard \& Arabie, 1979; Townsend, 1971). The backward-mask character, which appeared in the same position as each letter, consisted of the letters $H, S, T, X$ superimposed on each other.

The 24 regular blocks of trials represented all combinations of the following factors: spacing $(.1, .2, .5 \mathrm{deg})$, size (small, large), presence vs. absence of backward mask, and SOA (0,500 msec) $(3 \times 2 \times 2 \times 2=24)$. Five subjects were assigned to each of the four different random orderings (two were the reverse of the other two) of the 24 blocks (and trials within blocks). In each block, three practice trials preceded the 24 regular trials. The 24 regular blocks were preceded by a practice block, for a total of 675 trials.

Within each block, 12 regular trials were same and 12 were different. Each of the six letters was used twice on the same pairs. Likewise, six different pairs were repeated once each. Three different pairs were similar (i.e., the two letters belonged to the same subset) and three were dissimilar (i.e., the two letters belonged to different subsets). A different set of three dissimilar pairs was used on each of the four random orderings, so all 12 possible dissimilar pairs were used equally of ten across subjects.

Procedure. Each trial began with a .5 -sec presentation of the fixation mark alone. On simultaneous trials, the letter pair then appeared for $200 \mathrm{msec}$, followed immediately on masked trials by mask characters in the same letter positions for $33 \mathrm{msec}$. On sequential trials, the left letter in the pair appeared for $200 \mathrm{msec}$, followed immediately either by a mask character for $33 \mathrm{msec}$ and then the fixation mark alone for $267 \mathrm{msec}$ or by the fixation mark alone for $300 \mathrm{msec}$. The right letter then appeared for $200 \mathrm{msec}$, followed immediately on masked trials by the mask character for $33 \mathrm{msec}$. On all trials, after both letters and masks (when appropriate) had been presented, the fixation mark appeared alone until a response was made. No feedback was given on the accuracy of the response during the $.5-\mathrm{sec}$ interval between trials. There was a 5-sec interval between blocks of trials, which allowed the next set of trials to be read in from the host computer.

The subjects were instructed to keep their eyes focused at all times just above the fixation mark, between where the two letters would appear. The subjects were told to respond as rapidly as possible, but not at the expense of accuracy. For half of the subjects, the "same" response was assigned to the right-hand button, and the "different" response to the left-hand button, and the other half had the reverse hand assignment. With sequential presentation, RT was measured from the onset of the second letter in the pair. Trials with an RT greater than $3 \mathrm{sec}$ or less than $200 \mathrm{msec}$ were discarded prior to data analysis. Mean RT was computed for correct trials only.

\section{Results and Discussion}

Detailed RT and error data are presented in Table 1 for all combinations of factors (except masking). Before examining the spatial factor, the data on two preliminary questions will be addressed: (1) Does sequential presentation enhance the fast-same effect, and (2) does the sequential enhancement involve a sensitivity shift or a criterion shift?

Question 1: Sequential enhancement. As shown in Figure 1, responses to same (vs. different) pairs were faster $[F(1,19)=26.49, p<.001]$ but more errorful $[F(1,19)=16.80, p<.001]$. Sequential trials were slightly slower, $F \cong 0$, but significantly more accurate $[F(1,19)=12.52, p<.01]$ than simultaneous trials. The fast-same effect was three times as great on sequential as on simultaneous trials [ 47 vs. $15 \mathrm{msec}$; $\mathrm{F}(1,19)=14.61, \mathrm{p}<.01]$, but was still significant when simultaneous trials alone were considered $[F(1,19)=4.51, p<.05]$. Krueger $(1983)$ was somewhat skeptical about the existence of priming, which he found when letters were rarely or never repeated across trials, but not when such intertrial letter repetition was frequent. The present results laid these doubts to rest. We obtained a quite significant $(p<.01)$ and large $(32 \mathrm{msec})$ sequential enhancement, using a six-letter stimulus set, which permitted relatively little intertrial letter repetition. Thus, priming is indeed readily found when intertrial repetition is minimized.

Table 1

Experiment 1: Mean Response Time (RT; in Milliseconds) and Percentage of Error (PE) Rate by Stimulus-Onset Asynchrony (SOA), Letter Size, Interletter Spacing (in Degrees), and Trial Type

\begin{tabular}{|c|c|c|c|c|c|c|c|c|}
\hline \multirow[b]{3}{*}{ SOA } & \multirow[b]{3}{*}{ Letter Size } & \multirow[b]{3}{*}{ Spacing } & \multicolumn{6}{|c|}{ Trial Type } \\
\hline & & & \multicolumn{2}{|c|}{ Same } & \multicolumn{2}{|c|}{$\begin{array}{c}\text { Similar } \\
\text { Differént }\end{array}$} & \multicolumn{2}{|c|}{$\begin{array}{c}\text { Dissimilar } \\
\text { Different }\end{array}$} \\
\hline & & & $\mathrm{RT}$ & PE & RT & PE & RT & PE \\
\hline \multirow[t]{2}{*}{0 -msec } & Small & $\begin{array}{r}.1 \\
.2 \\
.5 \\
\text { All }\end{array}$ & $\begin{array}{l}679 \\
634 \\
642 \\
652\end{array}$ & $\begin{array}{l}6.06 \\
3.96 \\
4.17 \\
4.73\end{array}$ & $\begin{array}{l}709 \\
666 \\
665 \\
680\end{array}$ & $\begin{array}{l}1.67 \\
4.17 \\
0.83 \\
2.22\end{array}$ & $\begin{array}{l}657 \\
638 \\
626 \\
640\end{array}$ & $\begin{array}{l}2.08 \\
1.67 \\
1.67 \\
1.80\end{array}$ \\
\hline & Large & $\begin{array}{r}.1 \\
.2 \\
.5 \\
\text { All }\end{array}$ & $\begin{array}{l}605 \\
583 \\
588 \\
592\end{array}$ & $\begin{array}{l}3.12 \\
3.75 \\
2.71 \\
3.19\end{array}$ & $\begin{array}{l}630 \\
606 \\
619 \\
618\end{array}$ & $\begin{array}{l}3.37 \\
2.50 \\
3.75 \\
3.21\end{array}$ & $\begin{array}{l}634 \\
594 \\
603 \\
610\end{array}$ & $\begin{array}{l}2.92 \\
0.42 \\
1.67 \\
1.67\end{array}$ \\
\hline \multirow[t]{2}{*}{$500-\mathrm{msec}$} & Small & $\begin{array}{r}.1 \\
.2 \\
.5 \\
\text { All }\end{array}$ & $\begin{array}{l}636 \\
603 \\
604 \\
615\end{array}$ & $\begin{array}{l}3.12 \\
2.29 \\
1.89 \\
2.44\end{array}$ & $\begin{array}{l}685 \\
666 \\
655 \\
668\end{array}$ & $\begin{array}{l}1.67 \\
0.83 \\
1.67 \\
1.39\end{array}$ & $\begin{array}{l}644 \\
633 \\
629 \\
636\end{array}$ & $\begin{array}{l}0.42 \\
0.42 \\
1.67 \\
0.83\end{array}$ \\
\hline & Large & $\begin{array}{r}.1 \\
.2 \\
.5 \\
\text { All }\end{array}$ & $\begin{array}{l}578 \\
598 \\
622 \\
599\end{array}$ & $\begin{array}{l}2.50 \\
4.17 \\
3.96 \\
3.54\end{array}$ & $\begin{array}{l}661 \\
666 \\
683 \\
670\end{array}$ & $\begin{array}{l}2.50 \\
1.25 \\
0.83 \\
1.53\end{array}$ & $\begin{array}{l}633 \\
639 \\
651 \\
641\end{array}$ & $\begin{array}{l}1.25 \\
0.42 \\
1.67 \\
1.11\end{array}$ \\
\hline
\end{tabular}




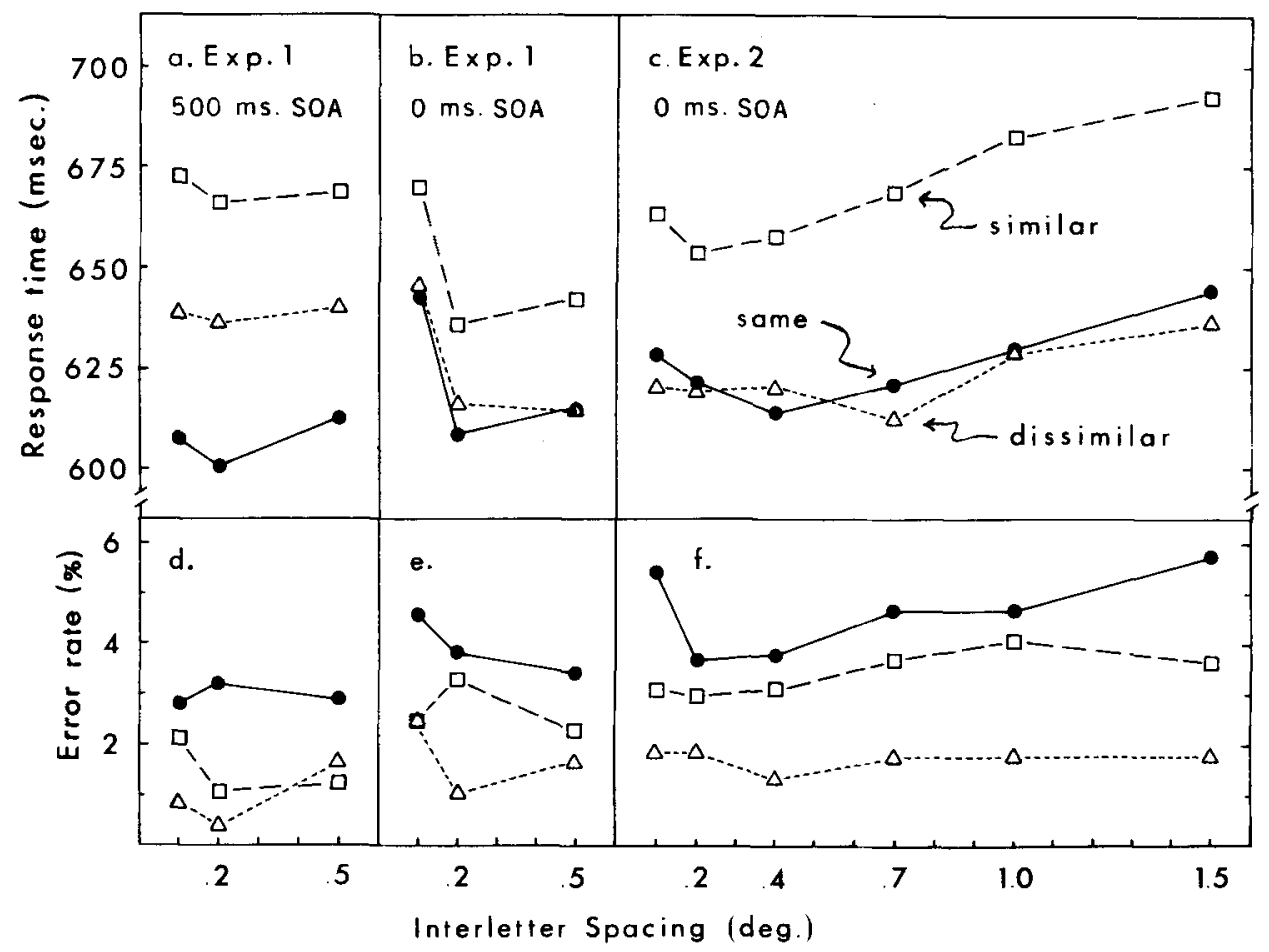

Figure 1. Experiments 1 and 2: Mean response time (in milliseconds) and percentage of errors by stimulus-onset asynchrony, interletter spacing, and trial type (same, similar different, dissimilar different).

Question 2: Sensitivity shift vs. criterion shift. If the sequential enhancement involves a criterion shift, then the preponderance of false-"different" errors (on same trials) ought to be much lower with sequential presentation. However, the same-different error disparity did not change with sequential (vs. simultaneous) presentation, $F \cong 0$. False-"different" errors (on same pairs) exceeded false-"same" errors (on different pairs) by $1.77 \%$ with sequential presentation and $1.74 \%$ with simultaneous presentation, indicating virtually perfect additivity between SOA and trial type on errors. The same-different error effect was significant on each type of presentation analyzed separately ( $p<.01$ in both cases). Thus, the present results add to the growing evidence (Krueger, 1983; Proctor \& Rao, 1983a) that priming reflects a change in the efficiency of encoding ( $\left.d^{\prime}\right)$ rather than a criterion shift ( $\beta$ ).

Question 3: Spatial factors. The question thus becomes whether the increase in the efficiency of encoding identical letter pairs on sequential trials stemmed from decreased spatial proximity. Close spacing increased $R T$ significantly $[F(2,38)=3.79$, $\mathrm{p}<.05]$, but it slowed same, similar different, and dissimilar different trials equally on simultaneous trials (see Figure 1b). Furthermore, the effect of spacing on each of the three trial types (same, similar, dissimilar) did not change with SOA $(F<1)$.
Close spacing did not increase errors overall, and it did not change the error disparity on trial type between simultaneous and sequential trials $(F<1)$. Thus, no spatial factor (e.g., reduced feature-specific inhibition or self-termination for sequentially presented letter pairs) can account for the sequential enhancement of the fast-same effect. Close spacing slowed RT significantly for small letters $[F(2,38)=$ $4.77, p<.05]$ but not for large letters $(F \cong 1)$, and thus exacerbated the difficulty in comparing small letters, which were responded to $29 \mathrm{msec}$ more slowly than large letters $[F(1,19)=15.64, p<.001$; see Figure 2].

Variation in letter size provided a further test of the self-termination factor. Large letters might encourage analytical, self-terminating comparisons, favoring the different judgment, with simultaneous presentation (Krueger, 1983). Contrary to this possibility, however, the fast-same effect was greater, not smaller, with large letters $[F(1,19)=9.80, p<$ $.01]$, and it was no greater with large letters on sequential (vs. simultaneous) trials. Krueger (1983, 1984) also found no effect of letter size on the relative fast-same effect for sequential vs. simultaneous presentation, and he concluded that single letters are always compared in holistic fashion.

Similarity effects. Different RT significantly increased (by $27 \mathrm{msec}$ ) for similar (vs. dissimilar) pairs 


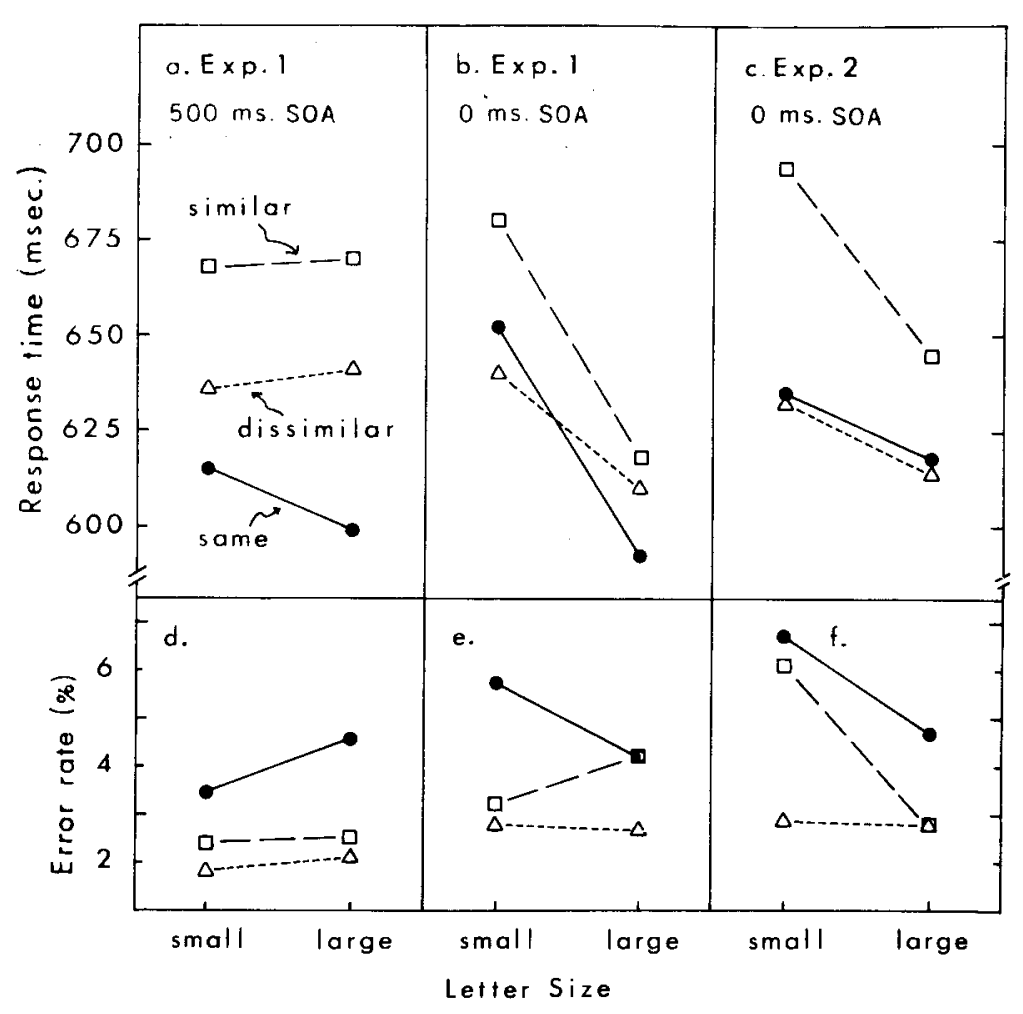

Figure 2. Experiments 1 and 2: Mean response time (in milliseconds) and percentage of errors by stimulus-onset asynchrony, letter size (small letters were .24 deg wide $x$ $.36 \mathrm{deg}$ high; large letters were $.72 \mathrm{deg}$ wide $\times 1.08 \mathrm{deg}$ high), and trial type (same, similar different, dissimilar different).

$[F(1,19)=84.33, p<.001]$, and the increase was significantly greater on small than on large different pairs [40 vs. $13 \mathrm{msec} ; \mathrm{F}(1,19)=6.00$, p $<.05]$, but, if anything, it was greater on sequential than on simultaneous trials ( 31 vs. $24 \mathrm{msec}, \mathrm{F} \cong 1$ ). The effect of visual similarity might have diminished if SOAs of $1 \mathrm{sec}$ or more had been used (Thorson, Hochhaus, \& Stanners, 1976), although recent evidence (Boles \& Eveland, 1983) indicates that the similarity effect would have lasted $2 \mathrm{sec}$ or more. There was a marginally significant tendency for increased similarity to increase errors (false-"same" responses) $[F(1,19)$ $=3.94, \mathrm{p}<.10$ ], which likewise did not diminish significantly with sequential (vs. simultaneous) presentation $(F \cong 0)$.

Obtaining just as strong a similarity effect with sequential presentation on both RT and errors indicates that visual codes were used as often on sequential as on simultaneous comparisons (see Boles \& Eveland, 1983; Crist, 1981), which contradicts Proctor's (1981) conclusion that sequential comparisons are performed on name codes. This indicates that priming depended not on a basic change in the way the stimuli were represented with sequential presentation, but instead on increased efficiency in detecting repeated letters at the visual or physical level.
The visual code may have been more efficient on sequential trials because it was more abstract (i.e., size invariant). On RT, letter size interacted significantly with SOA $[F(1,19)=5.71, p<.05]$. Large letters reduced RT on simultaneous trials (Figure $2 \mathrm{~b}$ ), but did not affect the speed of sequential judgments (Figure $2 \mathrm{a}$ ), in which the visual code appears to be size invariant.

Response competition. With simultaneous presentation, dissimilar different trials were as fast as same trials (Figure 1b), which is consistent with Eriksen, O'Hara, and Erikșen's (1982) response-competition model. They attributed the slow "different" response to competing matching features, which are not present on dissimilar different pairs. The Eriksen et al. model also is consistent with the greater number of false-same responses on similar than on dissimilar different pairs, but it does not explain the preponderance of false-"different" responses, which exceeded false-"same" responses even on similar different pairs.

Masking. Masking was used in order to increase the noise level and to limit rechecking, thereby decreasing the same-different $\mathrm{RT}$ disparity, but increasing the error disparity. As Table 2 shows, the backward mask slowed judgments significantly $[F(1,19)=$ 
Table 2

Experiment 1: Mean Response Time (RT; in Milliseconds) and Percentage of Error (PE) Rate by Stimulus-Onset Asynchrony (SOA), Letter Size, Interletter Spacing (in Degrees), and Trial Type

\begin{tabular}{|c|c|c|c|c|c|c|}
\hline \multirow[b]{3}{*}{ SOA } & \multirow[b]{3}{*}{ Letter Size } & \multirow[b]{3}{*}{ Masking } & \multicolumn{4}{|c|}{ Trial Type } \\
\hline & & & \multicolumn{2}{|c|}{ Same } & \multicolumn{2}{|c|}{ Different } \\
\hline & & & RT & PE & RT & PE \\
\hline \multirow[t]{6}{*}{ 0-msec (simultaneous) } & Small & & & & & \\
\hline & & No Mask & 641 & 5.14 & 645 & 2.36 \\
\hline & & Mask & 663 & 4.32 & 676 & 1.67 \\
\hline & Large & & & & & \\
\hline & & No Mask & 599 & 3.05 & 631 & 3.06 \\
\hline & & Mask & 585 & 3.33 & 598 & 1.80 \\
\hline \multirow[t]{6}{*}{500 -msec (sequential) } & Small & & & & & \\
\hline & & No Mask & 589 & 2.36 & 626 & 1.25 \\
\hline & & Mask & 640 & 2.51 & 679 & 0.97 \\
\hline & Large & & & & & \\
\hline & & No Mask & 581 & 2.92 & 639 & 1.39 \\
\hline & & Mask & 618 & 4.17 & 674 & 1.25 \\
\hline
\end{tabular}

4.38, $p<.05$, but only with sequential (vs. simultaneous) presentation $[F(1,19)=9.86, p<.01]$. On simultaneous trials analyzed separately, the mask had no effect on either $R T(F \cong 1)$ or errors $[F(1,19)=$ 2.87 , n.s.]. The mask apparently arrived too late (200 msec after stimulus onset) to prevent full encoding and comparison, and on simultaneous trials masking did not interact with trial type (same, different) on either RT or errors ( $F \cong 1$ in both cases). Proctor and Rao (1983b) also found no evidence for interference with rechecking on simultaneous trials, presumably because they, too, used a letter-mask SOA of $200 \mathrm{msec}$ or longer. Their results and ours indicate that the initial encoding and comparison, as well as any rechecking of the stimulus representation, occur well within $200 \mathrm{msec}$ of stimulus onset, which casts doubt on Krueger's (1978) proposal that each encoding-and-comparison pass lasts a full 200 msec.

On sequential trials analyzed separately, masking had a significant effect on $R T[F(1,19)=12.63$, p $<$ $.01]$ but not on errors $(F \cong 0)$. The second stimulus and the comparison itself escaped the effect of masking, judging by the null effect on simultaneous trials, so the main effect of masking on sequential trials apparently was to degrade the representation of the first stimulus. If so, both the RT and error disparities on same vs. different ought to have increased with masking (Krueger, 1978). However, masking did not interact with trial type (same, different) on either RT or errors ( $F \cong 1$ in both cases). The fastsame effect was identical $(47 \mathrm{msec})$ with and without masking, although the preponderance of false-" different" errors was larger with than without masking $(2.23 \%$ vs. $1.32 \%)$, as expected.

\section{EXPERIMENT 2}

Experiment 1 showed that: (1) sequential enhancement occurs, (2) it reflects increased efficiency in encoding identical letter pairs, and (3) temporal separation (priming) is responsible for the increased efficiency. However, the spatial factors (lateral interference; self-termination) may not have received a fair test because of the narrow range of interletter spacing used (.1 to $.5 \mathrm{deg})$. Therefore, Experiment 2, which used only simultaneous presentation, had a much wider range of spacings (.1 to $1.5 \mathrm{deg}$ ). Since the backward mask had no effect on simultaneous trials in Experiment 1, it was replaced by a manipulation of stimulus duration (100 vs. $200 \mathrm{msec}$ ). Task difficulty was increased further by intermixing (unblocking) the stimulus conditions, so that letter size and spacing were no longer predictable prior to each trial, and thus the subject could not overcome the effect of a wide spacing simply by moving his or her eyes between two known positions.

\section{Method}

There were 56 subjects. Data from six additional subjects were discarded, three because of equipment failure and three for exceeding an $8 \%$ error criterion. The method was the same as in Experiment 1, except for the following changes. The horizontal extent of a letter pair varied between $.58 \mathrm{deg}$ (small size, .1-deg spacing) and $2.94 \mathrm{deg}$ (large size, 1.5-deg spacing). The same three similarity subsets of letters were used again, except that a V,Y subset replaced the $L, T$ subset, because $L$ and $T$ were much less confusable in Experiment 1 than the other two letter subsets (H,M; $\mathrm{O}, \mathrm{D})$. All subjects received the same three similar different pairs (HM, OD, VY) and the same three dissimilar different pairs (HV, OM, DY). The 24 experimental conditions, representing all combinations of interletter separation $(.1, .2, .4, .7,1.0,1.5 \mathrm{deg})$, letter size (small, large), and pair duration $(100,200 \mathrm{msec})(6 \times$ $2 \times 2=24$ ), were used twice with each of the 12 letter pairs (six same, three similar, three dissimilar), giving a total of 576 regular trials. No experimental factor was blocked, and the SOA always was $0 \mathrm{msec}$ (simultaneous presentation). Seven subjects each received one of eight different random orderings of trials.

\section{Results and Discussion}

Detailed RT and error data are shown in Table 3 for all combinations of factors. As shown in Figure 1 , responses to same (vs. different) pairs were 
Table 3

Experiment 2: Mean Response Time (RT; in Milliseconds) and Percentage of Error (PE) Rate by Letter Size, Stimulus Duration, Interletter Spacing (in Degrees), and Trial Type

\begin{tabular}{|c|c|c|c|c|c|c|c|c|}
\hline \multirow[b]{3}{*}{ Letter Size } & \multirow[b]{3}{*}{ Duration } & \multirow[b]{3}{*}{ Spacing } & \multicolumn{6}{|c|}{ Trial Type } \\
\hline & & & \multicolumn{2}{|c|}{ Same } & \multicolumn{2}{|c|}{$\begin{array}{c}\text { Similar } \\
\text { Different }\end{array}$} & \multicolumn{2}{|c|}{$\begin{array}{l}\text { Dissimilar } \\
\text { Different }\end{array}$} \\
\hline & & & RT & $\mathrm{PE}$ & RT & $\mathrm{PE}$ & RT & $\mathrm{PE}$ \\
\hline \multirow[t]{2}{*}{ Small } & $100 \mathrm{msec}$ & $\begin{array}{r}.1 \\
.2 \\
.4 \\
.7 \\
1.0 \\
1.5 \\
\text { All }\end{array}$ & $\begin{array}{l}631 \\
624 \\
614 \\
628 \\
641 \\
662 \\
633\end{array}$ & $\begin{array}{l}7.32 \\
4.32 \\
4.76 \\
6.84 \\
5.21 \\
8.83 \\
6.21\end{array}$ & $\begin{array}{l}691 \\
690 \\
683 \\
693 \\
707 \\
740 \\
701\end{array}$ & $\begin{array}{l}4.76 \\
6.55 \\
5.06 \\
4.76 \\
7.44 \\
6.54 \\
5.85\end{array}$ & $\begin{array}{l}611 \\
616 \\
640 \\
612 \\
616 \\
643 \\
623\end{array}$ & $\begin{array}{l}2.38 \\
2.08 \\
1.19 \\
2.98 \\
2.08 \\
2.68 \\
2.23\end{array}$ \\
\hline & $200 \mathrm{msec}$ & $\begin{array}{r}.1 \\
.2 \\
.4 \\
.7 \\
1.0 \\
1.5 \\
\text { All }\end{array}$ & $\begin{array}{l}646 \\
624 \\
616 \\
631 \\
644 \\
662 \\
637\end{array}$ & $\begin{array}{l}6.13 \\
5.07 \\
3.42 \\
5.36 \\
5.82 \\
5.51 \\
5.22\end{array}$ & $\begin{array}{l}684 \\
669 \\
670 \\
688 \\
711 \\
706 \\
688\end{array}$ & $\begin{array}{l}4.46 \\
2.38 \\
3.87 \\
5.36 \\
5.36 \\
4.76 \\
4.37\end{array}$ & $\begin{array}{l}649 \\
629 \\
632 \\
627 \\
632 \\
672 \\
640\end{array}$ & $\begin{array}{l}2.38 \\
2.38 \\
1.49 \\
0.30 \\
0.60 \\
1.79 \\
1.49\end{array}$ \\
\hline \multirow[t]{2}{*}{ Large } & $100 \mathrm{msec}$ & $\begin{array}{r}.1 \\
.2 \\
.4 \\
.7 \\
1.0 \\
1.5 \\
\text { All }\end{array}$ & $\begin{array}{l}606 \\
609 \\
615 \\
608 \\
614 \\
636 \\
615\end{array}$ & $\begin{array}{l}4.91 \\
2.83 \\
3.27 \\
3.42 \\
4.61 \\
5.36 \\
4.07\end{array}$ & $\begin{array}{l}649 \\
624 \\
635 \\
635 \\
663 \\
670 \\
646\end{array}$ & $\begin{array}{l}2.38 \\
1.79 \\
1.19 \\
2.08 \\
1.79 \\
2.08 \\
1.89\end{array}$ & $\begin{array}{l}600 \\
607 \\
606 \\
607 \\
612 \\
610 \\
607\end{array}$ & $\begin{array}{l}1.79 \\
2.08 \\
1.49 \\
2.98 \\
2.98 \\
1.79 \\
2.18\end{array}$ \\
\hline & $200 \mathrm{msec}$ & $\begin{array}{r}.1 \\
.2 \\
.4 \\
.7 \\
1.0 \\
1.5 \\
\text { All } \\
\end{array}$ & $\begin{array}{l}629 \\
627 \\
610 \\
618 \\
622 \\
619 \\
621 \\
\end{array}$ & $\begin{array}{l}3.42 \\
2.53 \\
3.88 \\
3.27 \\
3.12 \\
\mathbf{3 . 4 2} \\
\mathbf{3 . 2 8} \\
\end{array}$ & $\begin{array}{l}630 \\
631 \\
641 \\
660 \\
651 \\
653 \\
644 \\
\end{array}$ & $\begin{array}{l}0.89 \\
1.19 \\
2.38 \\
2.68 \\
1.85 \\
1.19 \\
1.70\end{array}$ & $\begin{array}{l}620 \\
624 \\
601 \\
605 \\
656 \\
620 \\
621 \\
\end{array}$ & $\begin{array}{l}0.89 \\
0.89 \\
1.19 \\
0.89 \\
1.49 \\
0.89 \\
1.04 \\
\end{array}$ \\
\hline
\end{tabular}

faster by $19 \mathrm{msec}[\mathrm{F}(1,55)=20.75, \mathrm{p}<.001]$ and more errorful by $2.10 \%[F(1,55)=54.66, p<.001]$. As in Experiment 1, the spatial factors (lateral interference; self-termination) were tested by varying interletter spacing and letter size.

Interletter spacing. If the spatial factors are important, then the fast-same effect should be enhanced at wide interletter spacings. Very close and very wide spacing slowed $R T[F(5,275)=19.28, p<$ $.001]$ and increased errors $[F(5,275)=3.44, \mathrm{p}<.05]$, but the fast-same effect did not change across the range of spacings (.1 to $1.5 \mathrm{deg}$ ) used in Experiment 2 (F $<1$; see Figure 1c). Thus, spatial proximity appears to have no bearing on matching RT (at least for interletter spacings of $1.5 \mathrm{deg}$ or less). As in Experiment 1, a comparison between the two closest spacings indicated that closer spacing significantly slowed processing $[\mathrm{F}(1,55)=4.16, \mathrm{p}<.05]$, but did so equally for same and different trials. As shown in Figure 1f, errors also increased significantly at the closer spacing $[F(1,55)=8.20, \mathrm{p}<.01]$, although only on same (vs. different) pairs $[F(1,55)=5.89$, $\mathrm{p}<.05]$, perhaps reflecting feature-specific lateral interference (Bjork \& Murray, 1977), which the posi- tional uncertainty (intermixing of displays) in Experiment 2 may have encouraged (Keren, 1982).

Letter size. Large (vs. small) letters significantly reduced RT $[F(1,55)=68.89, \mathrm{p}<.001]$ and errors $[F(1,55)=50.79, p<.001$; see Figure 2$]$. The fastsame effect was smaller for large than for small letters $[12$ vs. $27 \mathrm{msec}, F(1,55)=10.67, \mathrm{p}<.01]$, although it was still significant on large letters analyzed separately $[F(1,55)=7.69, \mathrm{p}<.01]$. These results might seem to indicate that self-termination increased as letter size increased, thus favoring faster "different" responses. However, the opposite results were found in Experiment 1 (the fast-same effect increased rather than decreased for large letters), and Krueger $(1983,1984)$ found no effect of letter size on the speed advantage for same pairs. Furthermore, the self-termination factor was ruled out by the null effect of interletter spacing (Figure 1c), and, like Krueger (1983), we conclude that it does not account for the attenuation of the fast-same effect with simultaneous presentation on single-letter pairs.

Letter size interacted with similarity on RT. Different RT significantly increased (by $47 \mathrm{msec}$ ) for similar (vs. dissimilar) pairs $[F(1,55)=95.40, p<$ 
$.001]$, and the increase was significantly greater on small than on large different letters [63 vs. $31 \mathrm{msec}$; $F(1,55)=7.40, p<.05]$. Thus, the large size speeded performance more on simultaneous similar pairs than on simultaneous dissimilar pairs, regardless of whether trials were blocked (Experiment 1, Figure $2 \mathrm{~b}$ ) or intermixed (Experiment 2, Figure 2c). The large size also reduced errors more on similar (vs. dissimilar) pairs in the intermixed condition [Experiment 2, Figure 2f; $F(1,55)=35.79, p<.001$ ], but not in the blocked condition (Experiment 1, Figure 2e). No doubt the dissimilar pairs benefited less, as size increased, because they were about as fast and accurate in the small-size condition as they ever would be. For same pairs, large size reduced RT much more on blocked trials (Experiment 1, Figure 2b) than on intermixed trials (Experiment 2, Figure 2c). Thus, "same" responses are especially fast if the stimuli are quite easy to see (i.e., large) and if their placement is known in advance (i.e., blocked trials).

Duration. Shortening the stimulus duration had been expected to increase the noise level and to limit rechecking, thus reducing the fast-same effect and increasing the preponderance of false-"different" errors, but it did not alter either effect ( $F \cong 0$ in both cases). Proctor and Rao (1983b) obtained similar null results. Shortening the duration did significantly reduce overall $R T$ by $5 \mathrm{msec}[\mathrm{F}(1,55)=5.56, \mathrm{p}<.05]$ and increase errors by $0.89 \%[F(1,55)=20.04, p<$ $.001]$, which also replicates Proctor and Rao (1983b). Apparently, stimulus offset acted as a cue to respond immediately, resulting in faster, but less accurate, responses with the shorter display. The fact that the reduction in processing or rechecking on the briefer displays increased false-"same" responses as much as false-"different" ones poses a problem for the noisy-operator theory (Proctor \& Rao, 1983b). However, if processing was interrupted quite late, say during response organization, as the slight decrease in RT suggests, then the resulting motor confusions would increase both types of errors about equally.

\section{CONCLUSIONS}

The present study showed first that sequential presentation enhances the fast-same effect when intertrial letter repetition is minimized, thus laying Krueger's (1983) doubts to rest. Second, it showed that the enhancement reflects a sensitivity shift $\left(d^{\prime}\right)$ in encoding repeated letters, as Proctor (1981) claimed, rather than a criterion shift $(\beta)$, as Krueger and Shapiro (1981) claimed, because the preponderance of false"different" responses did not decrease with sequential presentation, as would have been expected if a bias were present. Krueger (1983) and Proctor and Rao (1983a) obtained similar results. Third, it showed that the sensitivity shift did not depend on spatial rather than temporal separation. The fast-same ef- fect might be attenuated on simultaneous trials if lateral interference was greater for same pairs or if spatial proximity encouraged faster, self-terminating processing on different trials. However, the fastsame effect was not affected by interletter spacing (which rules out both spatial factors) or by letter size (which rules out the self-termination factor). The present conclusions apply only to single-letter matches, however, since the self-termination factor can account for the attenuation of the fast-same effect on simultaneous multiletter comparisons (Krueger, 1984).

The present results thus support Proctor's (1981) contention that temporal separation leads to increased efficiency in encoding repeated letters. Contrary to Proctor, however, we found that sequential matches are performed on visual codes rather than name codes, and thus the priming must be at the visual or physical level. Visual similarity effects were just as evident on sequential trials as on simultaneous trials. Boles and Eveland (1983) and Crist (1981) found that a visual code is used even in nominalidentity matching. Their subjects apparently generated the alternative lettercase to match nominally identical pairs, thus bypassing the need to compare name codes. In the present study, the visual code was more abstract (size-invariant) on sequential (vs. simultaneous) trials, though, which might explain in part the increased efficiency in encoding repeated letters, since fewer features may be needed to determine that two abstract visual representations of a letter are the same.

Priming may depend more generally on predictability. Same RT was especially fast on simultaneous trials when the letters were large and their placement was known in advance (i.e., blocked trials). Perhaps high visibility and high predictability enable subjects to make very fast template matches to detect sameness (see Bamber's, 1969, identity reporter).

Consistent with the Eriksen, O'Hara, and Eriksen (1982) response-competition model, simultaneous trials were equally fast if no competing matches/ mismatches were present (dissimilar, same pairs), whereas more errors and slower responses occurred on different trials if competing matches were present (similar pairs) than if they were not (dissimilar pairs). However, the response-competition model must be supplemented by the noisy-operator theory (Krueger, 1978) in order to explain why false-"different" errors on same pairs consistently exceeded even false"same" errors on similar different pairs. Two findings pose problems for the noisy-operator theory, though. First, in Experiment 1, using a letter-mask SOA of 200 msec produced no interference with rechecking on simultaneous trials, which casts doubt on Krueger's (1978) proposal that each processing or rechecking pass lasts a full $200 \mathrm{msec}$. Second, in Experiment 2 , shortening the stimulus duration from 
200 to 100 msec prematurely terminated processing or rechecking (i.e., RT decreased, whereas errors increased), but did not increase false-"different" responses more than false-"same" responses. However, processing may have been interrupted quite late, that is, at response organization, and, for that reason, each button received an equal number of additional errors. In previous experiments, disabling the rechecking operation produced error effects consistent with the noisy-operator theory (Krueger \& Shapiro, 1982).

\section{REFERENCES}

BAmber, D. (1969). Reaction times and error rates for "same""different" judgments of multidimensional stimuli. Perception \& Psychophysics, 6, 169-174.

Bjork, E. L., \& MURray, J. T. (1977). On the nature of input channels in visual processing. Psychological Review, 84, 472-484.

Boles, D. B., \& Eveland, D. C. (1983). Visual and phonetic codes and the process of generation in letter matching. Journal of Experimental Psychology: Human Perception and Performance, 9, 657-674.

CRIST, W. B. (1981). Matching performance and the similarity structure of the stimulus set. Journal of Experimental Psychology: General, 110, 269-296.

Eriksen, C. W., \& Hoffman, J. E. (1973). The extent of processing of noise elements during selective encoding from visual displays. Perception \& Psychophysics, 14, 155-160.

Eriksen, C. W., O'Hara, W. P., \& Eriksen, B. A. (1982). Response competition effects in same-different judgments. Perception \& Psychophysics, 32, 261-270.

Eriksen, C. W., \& Rohrbaugh, J. W. (1970). Some factors affecting the efficiency of selective attention. American Journal of Psychology, 83, 330-342.

EsTES, W. K. (1982). Similarity-related channel interactions in visual processing. Journal of Experimental Psychology: Human Perception and Performance, 8, 353-382.

Gilmore, G. C., Hersh, M., Caramazza, A., \& Griffin, J. (1979). Multidimensional letter similarity derived from recognition errors. Perception \& Psychophysics, 25, 425-431.

Keren, G. (1982, November). The role of positional uncertainty in letter identification. Paper presented at the annual meeting of the Psychonomic Society, Minneapolis.

Krueger, L. E. (1978). A theory of perceptual matching. Psychological Review, 85, 278-304.

Krueger, L. E. (1983). Probing Proctor's priming principle: The effect of simultaneous and sequential presentation on same-different judgments. Journal of Experimental Psychology: Learning, Memory, and Cognition, 9, 511-523.

KRUEGER, L. E. (1984). Self-termination in same-different judgments: Multiletter comparison with simultaneous and sequential presentation. Journal of Experimental Psychology: Learning, Memory, and Cognition, 10, 271-284.

Krueger, L. E., \& Shapiro, R. G. (1981). A reformulation of Proctor's unified theory for matching task phenomena. Psychological Review, 88, 573-581.

Krueger, L. E., \& Shapiro, R. G. (1982). Search for a matching or mismatching letter pair. Perception \& Psychophysics, 31, 484-492.

Podgonny, P., \& Garner, W. R. (1979). Reaction time as a measure of inter- and intraobject similarity: Letters of the alphabet. Perception \& Psychophysics, 26, 37-52.

Proctor, R. W. (1981). A unified theory for matching-task phenomena. Psychological Review, 88, 291-326.

Procton, R. W., \& RAO, K. V. (1983a). Evidence that the samedifferent disparity in letter matching is not attributable to response bias. Perception \& Psychophysics, 34, 72-76.

Proctor, R. W., \& RAo, K. V. (1983b). Null effects of exposure duration and heterogeneity of difference on the same-different disparity in letter matching. Perception \& Psychophysics, 33, 163-171.

Proctor, R. W., \& RAO, K. V. (1983c). Reinstating the original principles of Proctor's unified theory for matching-task phenomena: An evaluation of Krueger and Shapiro's reformulation. Psychological Review, 90, 21-37.

Shepard, R. N., \& Arabie, P. (1979). Additive clustering: Representation of similarities as combinations of overlapping properties. Psychological Review, 86, 87-123.

Thorson, G., Hochhaus, L., \& Stanners, R. F. (1976). Temporal changes in visual and acoustic codes in a letter-matching task. Perception \& Psychophysics, 19, 346-348.

Townsend, J. T. (1971). Theoretical analysis of an alphabetic confusion matrix. Perception \& Psychophysics, 9, 40-50.

(Manuscript received October 3, 1983; revision accepted for publication June 25,1984 .) 